\title{
TRACHEOSTOMY IN THE ICU: HOPE OR DELUSION?
}

\author{
Ana Carolina Peçanha Antônio1, Ana Flávia Leivas²,3
}

\begin{abstract}
Introduction: Current literature suggests that tracheostomy has no impact on survival in unselected intensive care unit (ICU) patients, and that it actually transfers mortality from ICU to the ward.
\end{abstract}

Methods: Data from 71 adult subjects who underwent tracheostomy as part of their ICU management and were subsequently transferred to the ward were obtained retrospectively.

Results: During 2015, 104 subjects received tracheostomy. Thirty-two died during their initial ICU admission (30.4\%) and were excluded from analysis. Of the remaining 73 individuals, 28 died (38.3\%) in hospital. Most common diagnoses were sepsis (33.8\%) and neurological emergencies (23.9\%). Life-sustaining treatments were withheld or withdrawn in 25 decedents. Seven subjects died in later hospitalizations at our institution over the period recorded.

Conclusions: Tracheostomy may represent a burden after ICU discharge, involving high resource use and low survival rate. Efforts should be made to recognize patients who might clearly benefit from this technique to avoid unwanted prolonged mechanical ventilation.

Keywords: Tracheostomy; critical illness; decision-making

Placement of tracheostomy in the intensive care unit (ICU) is commonly believed to allow a more secure and manageable airway and to facilitate weaning from mechanical ventilation. Prolonged mechanical ventilation accounts for over half of tracheostomy indications ${ }^{1}$. Early tracheostomy is often undertaken due to severe neurological conditions, which are traditionally excluded from clinical trials ${ }^{2}$.

Current evidence shows that early tracheostomy does not improve any patient-centered outcome and increases the number of procedures being performed ${ }^{3,4}$. There is no specific duration of mechanical ventilation that demands tracheostomy. Some investigators suggest that although tracheostomy speeds ICU discharge and thus increases ICU survival, many of these patients die in the ward, resulting in a null effect on overall in-hospital mortality ${ }^{5}$.

Patients requiring prolonged mechanical ventilation have a 1-year mortality rate of $50-60 \%{ }^{6}$. However, at the time of tracheostomy for failure to liberate from the ventilator in the ICU, most patients and families lack a meaningful understanding of what lies ahead ${ }^{7}$. Perhaps for patients suffering from neurological injuries, more important is their potential for meaningful recovery, otherwise it is quite unlikely they would benefit from tracheostomy regardless of timing. Many patients and families are also unaware of alternatives to indefinite continuation of intensive care therapies, including limitation of life support while preserving the patient's comfort ${ }^{8-10}$.

The purpose of this investigation was to describe main characteristics and outcomes of tracheostomized patients discharged from ICU to the ward in a public hospital.

Clin Biomed Res. 2019;39(1):85-88

1 Serviço de Nutrologia, Hospital de Clínicas de Porto Alegre (HCPA). Porto Alegre, RS, Brasil.

2 Unidade de Terapia Intensiva, Hospital Santa Ana. Porto Alegre, RS, Brasil.

3 Unidade de Terapia Intensiva, Hospital Ernesto Dornelles. Porto Alegre, RS, Brasil.

Corresponding author: Ana Carolina Peçanha Antônio aantonio@hcpa.edu.br Hospital de Clínicas de Porto Alegre (HCPA)

Rua Ramiro Barcelos, 2350. 90035-903, Porto Alegre, RS, Brasil. 


\section{METHODS}

We conducted a retrospective observational investigation of data collected from electronic medical records. We included all adult subjects who underwent tracheostomy as part of their ICU management and were subsequently transferred to the ward in 2015 - date of ICU discharge was used as inclusion criterion, even if tracheostomy had been performed before that. The setting was four adult medical-surgical ICUs (44 beds) at a tertiary care public hospital in southern Brazil. Individuals who died in ICU at first admission were excluded. Demographic data, diagnoses on admission, comorbidities, duration of mechanical ventilation, ICU length of stay, end-of-life decisions and mortality were retrieved.

Results were expressed as mean and standard deviation, median and interquartile range, and proportions, as appropriate. The normal distribution of the various parameters was investigated observing the distribution of data and the Shapiro-Wilk test. We used the Fisher exact test to compare proportions and the Mann-Whitney $U$ test or t-test to compare continuous variables according to their distribution. A post hoc analysis was performed comparing living and deceased individuals by the end of 2015 according to their clinical characteristics. A p-value $<0.05$ was taken to be statistically significant. Statistical analysis was performed with STATA, version 13.0.

\section{RESULTS}

From October 2014 to December 2015, 105 of a total of 1327 critically ill patients received surgical tracheostomy. Thirty-two died during their initial ICU admission (30.4\%) and therefore were excluded from analysis. The mean age of 73 included individuals was $56.9 \pm 17.7$ years, $52.1 \%$ were male and mean APACHE II score was $21.6 \pm 6.8$ points. Chronic neurologic disorders and cancer were main comorbidities (21.1\% and 14\%, respectively). Most common admission diagnoses were sepsis $(33.8 \%)$ and neurological emergencies (stroke, intracerebral hemorrhage, meningitis) (23.9\%). Length of ICU stay was $30.7 \pm 17$ days and total duration of mechanical ventilation was 23 (13-29) days. Patients spent a median of 15 (11-19) days on mechanical ventilation before undergoing tracheostomy. There were no reports of severe adverse events related to tracheostomy.

Four individuals were readmitted to the ICU within 48 hours of ICU discharge. Twenty-eight eventually died in hospital. Life-sustaining treatments were withheld or withdrawn in 30 tracheostomized patients. Seven subjects died in later hospitalizations at our institution over the period recorded. In-hospital mortality for individuals with at least one admission to ICU during 2015 was $48.1 \%$, whereas for this cohort of 73 subjects it was $57.7 \%$.

Table 1 shows the main characteristics of the cohort according to survival status by the end of the study period.

\section{DISCUSSION}

We presented a retrospective review of subjects receiving surgical tracheostomy during ICU care in our institution during a 1-year period. Despite the short period of observation and lack of comparison to other populations, we perceived that it might be a misunderstanding surrounding prognosis after tracheostomy decision. Before initiating another invasive procedure, a consideration of the patient's prognosis and burden of discomfort should be undertaken relative to their values and wishes for prolonged invasive care.

Unlike a previous trial ${ }^{11}$, only the motor component of the Glasgow coma scale at ICU discharge significantly differed between survivors and decedents in 2015, yet of no clinical relevance. Life-threatening adverse events directly related to placement or maintenance of tracheostomy were not reported. Early indication for the procedure was not an issue in our research.

One explanation for the growth of prolonged mechanical ventilation provision despite poor patient outcomes ${ }^{6}$ is that the decision to pursue this level of care may be based on inadequate surrogate-physician interactions, unrealistic expectations and poor communication $^{7}$. A survey ${ }^{12}$ reported physicians' general discomfort with withholding or withdrawing life support in the face of prognostic uncertainty. Intensivists might hesitate to communicate when the problems, treatment options, and prognoses are not well defined. Furthermore, surrogates often lack knowledge of patients' wishes for life support and have poor comprehension of their medical problems ${ }^{13}$. In a prospective observational study ${ }^{10}$, only $21 \%$ of surrogates reported physicians had discussed potential consequences of tracheostomy placement including procedural risks, impact on discharge disposition, need for long-term ventilator support, and feeding route. Families often misinterpret the recommendation of tracheostomy as a positive event and a sign of hope for full recovery ${ }^{14}$. Less educated subjects are at higher risk of receiving less information about the potential outcomes of treatment ${ }^{8}$. In Brazil, physicians from 11 university-affiliated ICUs said they would do differently in $44 \%$ of cases from what they believed was best for the patient, but legal fears followed by team and societal opinion still impact their end-of-life decisions ${ }^{15}$. Therefore, content of physician-surrogate 
Table 1: Characteristics of study cohort according to survival status.

\begin{tabular}{|c|c|c|c|}
\hline Tracheostomized patients after ICU discharge $(n=71)^{*}$ & Living in $2015(n=36)^{*}$ & Deceased $(n=35)$ & $p$ \\
\hline Age (years) & $52(41-64)$ & $62.5(50-71.7)$ & 0.04 \\
\hline Female gender & 36 & 35 & 0.64 \\
\hline Time to tracheostomy (days) & $15(12-19)$ & $12.5(8.7-16.7)$ & 0.59 \\
\hline Total MV duration (days) & $26(16-33)$ & $19.5(12.2-28)$ & 0.33 \\
\hline APACHE II (score) & $20(15.5-25.5)$ & $22(21-25)$ & 0.048 \\
\hline SOFA (score) & $7(4-11)$ & $6(3.2-9)$ & 0.76 \\
\hline Length of ICU stay (days) & $33(20-41)$ & $21(15.2-32.7)$ & 0.13 \\
\hline Length of hospital stay (days) & $69(51-84)$ & $57(34-91)$ & 0.07 \\
\hline VAP diagnosis & 19 & 17 & 0.81 \\
\hline RRT at ICU discharge & 8 & 9 & 0.79 \\
\hline Copious secretions at ICU discharge & 12 & 17 & 0.26 \\
\hline $\begin{array}{l}\text { Need of intermittent positive pressure ventilation at ICU } \\
\text { discharge }\end{array}$ & 8 & 5 & 0.54 \\
\hline Limitation of therapeutic efforts & 4 & 26 & $<0.001$ \\
\hline Motor GCS at ICU discharge & $6(5-6)$ & $5.5(1-6)$ & 0.008 \\
\hline Admission due to stroke, $\mathrm{SAH}$ or meningitis & 3 & 10 & 0.03 \\
\hline $\mathrm{BMI}>30\left(\mathrm{~kg} / \mathrm{m}^{2}\right)$ & 5 & 5 & 1 \\
\hline Prior neurological sequelae & 3 & 9 & 0.4 \\
\hline COPD & 4 & 4 & 0.5 \\
\hline Heart failure & 3 & 2 & 1 \\
\hline Neoplasia & 2 & 8 & 0.046 \\
\hline
\end{tabular}

*Excluding 2 patients who were still hospitalized by the time we had concluded data collection. Data are presented as median (interquartile range), mean $\pm S D$ or $n(\%)$. ICU = intensive care unit; MV = mechanical ventilation; APACHE II = Acute Physiology and Chronic Health Evaluation II; SOFA = Sequential Organ Failure Assessment; VAP = ventilator-associated pneumonia; RRT = renal replacement therapy; GCS = Glasgow coma scale; $\mathrm{SAH}=$ subarachnoid hemorrhage; $\mathrm{BMI}=$ body mass index; $\mathrm{COPD}$ = chronic obstructive pulmonary disease.

communication is often inadequate for fully shared decision-making.

As expected, tracheostomy was a marker of higher mortality. What amount of such poor outcomes could be anticipated and honestly disclosure to decision-makers? Similar to another prospective study ${ }^{9}$, despite poor outcomes, limitation of disproportionate care occurred late in the present cohort. Our findings indicate a serious need to improve end-of-life care planning. The default strategy to prescribe tracheostomy and postpone discontinuation of life-prolonging therapies on a large proportion of neurologic injured and cancer patients implies an urge for comprehensive redefinition of goals.

Limitations of our investigation are worth noting. The association between clinical characteristics and outcomes is merely hypothesis-generated as it was not an endpoint defined a priori. We were unable to make any further inferences regarding end-of-life decisions owing to serious lack of information on medical records regarding family meetings and patient and proxy preferences. We did not interview ICU physicians to document their personal views regarding long-term prognosis for chronic critical illness. Data regarding decannulation, quality of life and chronic disability of survivors are also absent. There is no outreach team at the medical center that could assist tracheostomized patients after ICU discharge, and this deserves additional caution regarding generalizability.

A recently published mortality prediction model for prolonged mechanical ventilation may inform the discussion between surrogates and clinicians and improve prognostic accuracy ${ }^{16}$. We must be prepared to discuss the limitations of technology to cure and provide comfort care to patients and families. Tracheostomy and other potentially disproportionate interventions should never be driven by default.

\section{CONCLUSION}

Tracheostomy may represent a burden after ICU discharge, involving high resource use and low survival rate. Indication for tracheostomy should be cautious, and efforts should be made to recognize patients who might clearly benefit from this technique to avoid unnecessary and unwanted prolonged mechanical ventilation. All the decisions we make in the ICU have an important impact on future care needs. Even if earlier communication about expected outcomes does not change decision-making at the 
outset, such communication may help prepare patients and families for events, discussions, and decisions they are likely to face later.

Knowledge of characteristics and outcomes may assist in identifying interventions to reduce the need for tracheostomy or improve outcomes. In this sense, larger and prospective cohorts are needed.

\section{Disclaimer}

The authors have no commercial associations which impact this work.

\section{Conflicts of Interest}

The authors declare no conflicts of interest.

\section{REFERENCES}

1. Vargas $M$, Sutherasan $Y$, Antonelli $M$, Brunetti I, Corcione A, Laffey JG, et al. Tracheostomy procedures in the intensive care unit: an international survey. Crit Care. 2015;19(1):291. http://dx.doi.org/10.1186/s13054-0151013-7. PMid:26271742.

2. Young D, Harrison DA, Cuthbertson $\mathrm{BH}$, Rowan K. Effect of early vs late tracheostomy placement on survival in patients receiving mechanical ventilation: the TracMan randomized trial. JAMA. 2013;309(20):21219. http://dx.doi.org/10.1001/ jama.2013.5154. PMid:23695482.

3. Szakmany T, Russell P, Wilkes AR Hall JE. Effect of early tracheostomy on resource utilization and clinical outcomes in critically ill patients: metaanalysis of randomized controlled trials. Br J Anaesth. 2015;114(3):396405. http://dx.doi.org/10.1093/bja/ aeu440. PMid:25534400.

4. Meng L, Wang C, Li J, Zhang $\mathrm{J}$. Early vs late tracheostomy in critically ill patients: a systematic review and meta-analysis. Clin Respir J. 2016;10(6):684-92. http:// dx.doi.org/10.1111/crj.12286. PMid:25763477.

5. Fernandez R, Bacelar N, Hernandez G, Tubau I, Baigorri F, Gili G, et al. Ward mortality in patients discharged from the ICU with tracheostomy may depend on patient's vulnerability. Intensive Care Med. 2008;34(10):1878-82. http://dx.doi. org/10.1007/s00134-008-1169-6. PMid:18521568.

6. Carson SS, Kahn JM, Hough CL, Seeley EJ, White DB, Douglas IS, et al. A multicenter mortality prediction model for patients receiving prolonged mechanical ventilation. Crit Care Med. 2012;40(4):11716. http://dx.doi.org/10.1097/ CCM.0b013e3182387d43. PMid:22080643.

7. Nelson JE, Mercado AF, Camhi SL, Tandon N, Wallenstein S, August GI, et al. Communication about chronic critical illness. Arch Intern Med. 2007;167(22):250915. http://dx.doi.org/10.1001/ archinte.167.22.2509. PMid:18071175.

8. White DB, Engelberg RA, Wenrich MD, Lo B, Curtis JR. Prognostication during physicianfamily discussions about limiting life support in intensive care units. Crit Care Med. 2007;35(2):4428. http://dx.doi.org/10.1097/01. CCM.0000254723.28270.14. PMid:17205000.

9. Camhi SL, Mercado AF, Morrison RS, Du Q, Platt DM, August GI, et al. Deciding in the dark: advance directives and continuation of treatment in chronic critical illness. Crit Care Med. 2009;37(3):91925. http://dx.doi.org/10.1097/ CCM.0b013e31819613ce. PMid:19237897.

10. Cox CE, Martinu T, Sathy SJ, Clay AS, Chia J, Gray AL, et al. Expectations and outcomes of prolonged mechanical ventilation. Crit Care Med. 2009;37(11):2888-94, quiz 904. http://dx.doi.org/10.1097/ CCM.0b013e3181ab86ed. PMid:19770733.

11. Gerber DR, Chaaya A, Schorr CA, Markley D, Abouzgheib W. Can outcomes of intensive care unit patients undergoing tracheostomy be predicted? Respir Care. 2009;54(12):1653-7. PMid:19961630.

12. Palda VA, Bowman KW, McLean RF, Chapman MG. "Futile" care: do we provide it? Why? A semistructured, Canada-wide survey of intensive care unit doctors and nurses. J Crit Care. 2005;20(3):207-13. http:// dx.doi.org/10.1016/j.jcrc.2005.05.006. PMid:16253788.

13. Cohen $S$, Sprung $C$, Sjokvist $P$, Lippert A, Ricou B, Baras M, et al. Communication of end-of-life decisions in European intensive care units. Intensive Care Med. 2005;31(9):1215-21. http://dx.doi. org/10.1007/s00134-005-2742-x. PMid:16041519.

14. Nelson JE, Kinjo K, Meier DE, Ahmad $\mathrm{K}$, Morrison RS. When critical illness becomes chronic: informational needs of patients and families. $J$ Crit Care. 2005;20(1):79-89. http:// dx.doi.org/10.1016/j.jcrc.2004.11.003. PMid:16015521.

15. Forte DN, Vincent JL, Velasco IT, Park M. Association between education in $\mathrm{EOL}$ care and variability in EOL practice: a survey of ICU physicians. Intensive Care Med. 2012;38(3):40412. http://dx.doi.org/10.1007/s00134011-2400-4. PMid:22222566.

16. Hough CL, Caldwell ES, Cox CE, Douglas IS, Kahn JM, White DB, et al. Development and validation of a mortality prediction model for patients receiving 14 days of mechanical ventilation. Crit Care Med. 2015;43(11):233945. http://dx.doi.org/10.1097/ CCM.0000000000001205. PMid:26247337. 